\title{
Om medikaliseringen av svensk missbrukarvård
}

\author{
ANDERS BERGMARK
}

\begin{abstract}
Under de senaste 10 åren har propåerna om en radikal omorganisering av svensk missbrukarvaird vuxit sig allt starkare. Den allmänna inriktningen hos dessa påtryckningar har utgjorts av en medikalisererande argumentation beträffande den vetenskapliga kunskapen om missbruk och behandling: I denna artikel granskas några av medikaliseringsdiskursens mest centrala argument.
\end{abstract}

\section{Inledning}

Det är ett välkänt faktum att vården av missbrukare i Sverige och i norden (Finland, Norge men inte Danmark) till skillnad från majoriteten av andra västländer under en relativt lång tid har karakteriserats av ett socialt perspektiv avseende den grundläggande karaktären hos olika typer av missbruksproblem (Bruun 1971; Takala \& Lehto 1992). Detta har medfört att också det faktiska handhavandet av missbruksproblem i huvudsak har varit en angelägenhet för

Anders Bergmark, professor, Inst. för socialt arbete, Stockholms universitet. socialarbetare snarare än medicinsk personal. Samtidigt är det också mycket tydligt att denna ordning har varit utsatt för ett relativt hårt tryck under en relativt lång tid tillbaka. Det är nu mer än 10 år sedan som Statens beredning för medicinsk utvärdering (SBU) publicerade sin omfattande kunskapsöversikt beträffande behandling av alkohol- och narkotikaproblem: "Behandling av alkohol- och narkotikaproblem. En evidensbaserad kunskapssammanställning" (SBU 2001, reviderad engelskspråkig version, Berglund et al. 2003), som i allt väsentligt kom att utgöra den huvudsakliga vetenskapliga grunden för de nationella riktlinjerna för missbruks- och beroendevård som Socialstyrelsen publicerade 
under 2007. Bägge dessa dokument har en uttalad ambition att utifrån en vetenskaplig grund ange hur alkohol- och drogproblem skall behandlas. I SBU:s rapport framförs att rapporten utgör ett genomarbetat vetenskapligt underlag som möjliggör en radikal omorganisering av den svenska missbrukarvården - ett underlag för att "överföra resurser från ineffektiva behandlingsmetoder till metoder som är dokumenterat effektiva (SBU 2001, s. 26, vol. 1).

I ett mer samtida dokument - publicerat 10 år efter SBU:s kunskapssammanställning - går den s.k. missbruksutredningen ett steg längre - och rekommenderar att "Landstinget ska i egenskap av huvudman för hälso- och sjukvården ansvara för behandling" (SOU 2011:35, s. 128). Förslaget ifråga medför att behandling inte längre skall tillhandahållas inom socialtjänstens ramverk och utgör därmed ett radikalt brott med den långvariga icke-medicinskt inriktade vård av missbrukare som nämnts ovan. Utredningen framför flera olika typer av skäl till stöd för detta förslag. Några av dessa framställs som att de har vetenskaplig karaktär, under det att andra kan betraktas som baserade på organisatoriska och konsumentorienterade bevekelsegrunder.

Det är mot denna bakgrund den fortsatta framställningen avser att beskriva och diskutera på vilka sätt och med vilken sakmässig legitimitet diskursen kring den vetenskapliga grunden för behandling av missbrukare har förändrat förutsättningarna för att bedriva behandling utanför en medicinsk konceptualisering. Därmed kan framställningen också inordnas i den relativt omfattande samhällsvetenskapliga genre som har "medikaliseringsprocesser" som sitt primära studieobjekt. Det viktigaste standardverket på detta område: "Deviance and medicalization - from badness to sickness", publicerades för mer än trettio år sedan av Conrad och Schneider (1980).

\section{Den medicinska modellen}

I och med att frågan om specifika behandlingsinterventioners effekter inom missbruksområdet fördes upp på dagordningen i slutet av 1980-talet lanserades också en forskningstradition beträffande psykosociala behandlingsinterventioner organiserade i linje med en medicinsk modell. Det vill säga ett förfarande som medför att enskilda studier utformades i enlighet med ett schema där specifikt utvalda interventioner riktas mot patologiska processer eller andra biologiska tillkortakommanden som har blivit identifierade via tillförlitliga diagnoser/mätprocedurer. Den medicinska modellens undersökningsdesign skattar effekten av en given intervention genom att jämföra det relativa utfallet av densamma på individer som fördelats slumpmässigt på experimentinterventionen respektive ett kontrollförfarande (RCT, Randomized Controlled Trial). En modell av denna typ, som historiskt skördat betydande framgångar när det gäller infektionssjukdomar, framstår också som helt rimlig när det gäller kända eller väl beskrivna fysiska problem som behandlas med farmaka. Däremot har modellen inte varit lika framgångsrik när det gäller att identifiera vetenskapligt solida och differentierande effekter av psykosociala interventioner. Detta tillkortakommande visavi det medi- 
cinska området sammanhänger med största sannolikhet med det faktum att medicinska interventioner i huvudsak undersöks via randomiserade experiment där kontrollgruppen erhåller en placebointervention, som inte kan särskiljas från experimentinterventionen. Iscensättning av experimentet är i normalfallet också dubbelblint (dvs. vare sig behandlare eller klienter vet vilket behandlingsalternativ som utgör experimentinterventionen). Det dubbelblinda arrangemanget, som i sig utgör ett mycket starkt krav inom den medicinska kontexten, kan i princip inte iscensättas när det gäller psykosociala behandlingsinterventioner, detta då interventionens identitet inte kan döljas för vare sig behandlare eller klient. Att den dubbelblinda undersökningsdesignen inte kan genomföras när det gäller att fastställa effekter av psykosociala interventioner medför givetvis inte att problemet som sådant försvinner. Trots problemets dignitet har många forskare kommit att acceptera undersökningsdesigner där experimentinterventioner jämförs med inga insatser alls (väntelista, kortfattad information $\mathrm{mm}$ ) eller med det som i internationell litteratur betecknas som "treatment as usual" (TAU). På svenska betecknas den senare termen ofta och lite olyckligt som "standardbehandling" eller "sedvanlig behandling" (se, t.ex. SBU 2001) vilket utgör ett problem i så måtto att det antyder att kontrollinterventionen skulle vara standardiserad, när det i själva verket är tvärtom; "Treatment as usual" är alltid kontextberoende och innehåll och intensitet varierar med den kontext inom vilken behandlingsexperimentet genomförs (Bergmark 2001; Bergmark 2008c).
Bruce Wampold (2001) har på ett övertygande sätt (via empiriska re-analyser av tidigare översikter på psykoterapiområdet) visat att i den utsträckning sammanfattande analyser av behandlingseffekter baseras på jämförelser med ingen behandling eller TAU kommer man i allmänhet identifiera relativt påtagliga effekter för olika psykoterapeutiska interventioner. Men i de fall översikter baseras på experiment där interventioner som är avsedda ett ha effekt (de är bona fide) ställs mot varandra kan man i normalfallet inte identifiera några skillnader, denna frånvaro av effekter mellan olika typer av interventioner som är avsedda att vara effektiva, refereras ofta till som "the Dodo bird verdict" eller "the outcome equivalence paradox". Den skillnad som finns mellan de olika typerna av jämförelser antyder att det finns en placebofaktor också när det gäller psykosociala interventioner och att denna (kontextuella) faktor kontrolleras på ett rimligt sätt, när behandlingsinterventioner levereras av individer som har en positiv inställning till densamma (Bergmark 2008c). Sammantaget betyder detta att den medicinska modellen och därmed föreställningen om specifika verkningsmekanismer inte har något starkt stöd i den aktuella forskningen kring psykosociala interventioner för missbruksproblem.

\section{Sbu-studien}

Översikten från SBU (2001) är omfångsmässigt ett imponerande arbete som omfat$\operatorname{tar} 850$ sidor fördelade på två volymer som täcker ett flertal olika frågeställningar rela- 
terade till behandling av alkohol- och narkotikamissbruk. SBU:s översikter baseras också, helt i linje med områdets mer ortodoxa metodologi, på omfattande litteratursökningar i relevanta internationella databaser och de studier som inkluderas i översikter utgörs i huvudsak av RCT:s. Det föreligger dock en påtaglig, och i många stycken anmärkningsvärd, skillnad mellan SBU:s översikt beträffande alkoholproblem respektive narkotikaproblem. Generellt gäller att översikten beträffande alkoholproblem i allmänhet försökt handskas med den typ av grundläggande metodologiska problem som är relaterade till en variation beträffande interventionerna för jämförelsegrupperna, graden av problembelastning hos undersökningsgrupperna och en någorlunda relevant avgränsning av olika typer av behandlingsinterventioner (dock utan att i det faktiska genomförandet uppvisa en genomgående systematik). Dessa ambitioner återfinns överhuvudtaget inte i översikten beträffande narkotikaproblem. Men då de metodologiska ambitionerna beträffande översikten för alkoholproblem inte iscensattes på ett systematiskt sätt, blev slutresultat i stort sett detsamma; de genomförda analyserna på såväl alkohol-som narkotikasidan karakteriseras av resultat som till väsentliga delar är en följd av en bristande metodologisk skärpa (det gäller framförallt frånvaron av en rimlig hantering av olika typer av kontrollgruppsförfarenden, se ovan). Undertecknad har i ett flertal fall (Bergmark 2001; 2008a; 2010) på ett mer utförligt sätt redovisat invändningar såväl mot studiens metodologi och de resultat som anförts. Därmed finns det inte heller några skäl att upprepa desamma. I detta sammanhang fokuserar analysen istället på de institutionella förhållanden som tycks producera en medikalisering som delvis är av en annan typ än den som Conrad och Schneider ägnade sina studier åt i början av 1980-talet. Undertiteln på Conrad och Schneiders bok är "from badness to sickness" vilket betecknar en process där moraliskt tveksamma handlingsmönster som t.ex. dryckenskap (badness) transformeras till en sjukdom och ett objekt för den medicinska professionen.

När det gäller SBU:s översikt för behandling av alkohol- och narkotikaproblem är situationen delvis annorlunda i den meningen att det inte är en moralisk konceptualisering som skall utrangeras, utan snarare en ovetenskaplig verksamhet som skall ersättas med en vetenskapligt säkrad praktik när det gäller effekterna av densamma. Det citat från SBU-studien som anfördes inledningsvis kan i en mer utförlig form belysa transformationens karaktär: "Det finns därför ett utrymme att förbättra vården genom att dels överföra resurser från ineffektiva behandlingsmetoder till metoder som är dokumenterat effektiva och dels att förstärka de områden som tillämpar evidensbaserade metoder" (SBU 2001, sid. 26, vol. 1). Det torde inte råda något som helst tvivel om att undertexten här är att det är hos socialtjänsten de ineffektiva metoderna är anrikade och att de redan närvarande evidensbaserade metoderna återfinns inom den medicinska sfären.

Det finns en viss ironi i det faktum att under det att kraven på etablerandet av en vetenskapligtlevidensbaserad praktik inom socialtjänstens ansvarsområden här 
artikuleras med ökande styrka samtidigt som SBU:s studie i många stycken karakteriseras av en påtaglig brist på vetenskaplig kvalitet.

\section{Missbruksutredningen}

Missbruksutredningens slutbetänkande omfattar nästan 1000 sidor och lägger fram mer än 70 olika förslag. Utöver slutbetänkandet har utredningen också publicerat en forskningsbilaga på 880 sidor, "Missbruket, kunskapen, vården" (SOU 2011:6, vilken beskrivs som det vetenskapliga underlaget för utredningens analys och förslag) och ytterligare 8 rapporter på sammanlagt 614 sidor. Som påpekats i det föregående är utredningens mest genomgripande förslag att all behandling skall utföras inom ramen för landstingets verksamhet och utgör därmed en möjlig slutpunkt för den långvariga traditionen av en icke-medicinskt inriktad vård av missbrukare i Sverige. Utredningens övergripande målsättning anges till "att skapa en kunskapsbaserad missbruks- och beroendevård som utgår från den enskildes behov" (s. 73). Till stöd för sitt förslag att utgå från den enskildes behov anför utredningen här ett resultat från en enkätstudie som föreges ha tillfrågat 3000 individer med missbruks- eller beroendeproblem var de helst vill söka hjälp för sina problem; endast fem procent av de tillfrågade anger därvid att de önskar hjälp från socialtjänsten. Här har dock utredarna, på flera olika sätt, missförstått de omständigheter som de betraktar som ett stöd för identifikationen av den enskildes behov. För det första är de tillfrågade inte personer med ett faktiskt missbrukseller beroendeproblem, de aktuella frågorna om vårdpreferenser har riktats till en normalpopulation inom den s.k. "Monitorundersökningen" där ett mycket litet antal individer anger att de har missbruks- eller beroendeproblem. Detta innebär att svaren avspeglar vad normalkonsumenter anser att de borde göra i det fall att de hade ett missbruksproblem, inte vad faktiska missbrukare har för preferenser när det gäller vårdgivare. Utredarna begår ytterligare ett misstag när de med utgångspunkt i ett tänkande baserat på den medicinska modellen, likställer alkoholproblem med depression. Utredarna anför som ett problematiserande exempel att år 2009 hämtade 19000 personer ut minst en daglig dygnsdos under 90 dagar av något av de tre läkemedel som är godkända för behandling av alkoholproblem. Motsvarande siffror för depressionsbehandling är att 612000 personer fick minst en daglig dygnsdos under 90 dagar av ett läkemedel godkänt för depressionsbehandling. Exemplet är uppenbarligen tänkt att illustrera i hur hög utsträckning alkoholproblem är underbehandlade i jämförelse med depression. Men jämförelsen tar sin utgångspunkt $\mathrm{i}$ att dessa båda tillstånd är jämförbara, en förutsättning som knappast är för handen. Majoriteten av de som har en depression vill i de allra flesta fall bli av med den och de söker av detta skäl vård för sina besvär. Detta är inte fallet med de hundratusentals individer som utredningen identifierar som vårdbehövande för sina alkoholproblem. En stor andel av denna "dolda grupp" tycker med ganska stor säkerhet att de inte har några alkoholproblem och i den utsträckning de medger att de 
har dylika problem uppfattas de inte som tillräckligt allvarliga för att de skall försöka förändra sina alkoholvanor.

Utredningens logik bygger på föreställningen om ett omfattande uppdämt konsumentbehov av den vård som levereras av landstinget, särskilt läkemedelsbaserad vård. När denna missuppfattning kombineras med uppgiften att en stor majoritet av missbrukarna önskar få vård $i$ landstingets regi, ligger vägen öppen för utredningens förslag att lägga all behandling inom landstingens domäner. Men det är lätt att inse att den faktiska situationen för dagens missbrukarvård utgör ett starkt empiriskt argument till varför utrednings förslag bör avvisas. Om det vore så att 250000 individer med påtagliga alkoholproblem efterfrågade behandling och $\mathrm{i}$ allt väsentligt ville ha denna behandling levererad av landstinget skulle det finnas betydande köer för sådan vård. Också en av utredningens egna rapporter (Missbruksutredningen 2009) konstaterar att det inte föreligger några sådana köer. Givet att en stor majoritet av befolkningen anger att de skulle föredra medicinsk vård för alkoholproblem i det fall de hade några sådana, varför söker då så relativt få individer denna vård, den finns ju redan idag?

Utredningen anför också att den nuvarande ordningen utmanas av den vetenskapliga kunskapsutvecklingen på området; att ny kunskap har medfört att missbruk och beroende i allt högre grad kommit att betraktas som en sjukdom snarare än ett socialt problem (vilket implicit skulle tala för att landstingen skulle ta över ansvarat för behandling). Här anknyter utredningen, om än i ospecifika ordalag, till en av de mest tydliga tendenserna inom den internationella forskningen kring missbruk - att missbruk i vilken form det än må vara månde - skall betraktas som en hjärnsjukdom.

\section{"Behavioral addictions" och hjärnans belöningssystem}

Den relativt nya tendensen att identifiera icke-substansanknutna "beteende addiktioner" i termer av formella diagnoser är i många stycken ett tydligt tecken på en begreppslig omorientering när det gäller synen på missbruk. En dylik nyordning öppnar upp för en medikaliserande problematisering av en lång rad beteenden. Den teoretiska basen för denna utveckling har i huvudsak emanerat från forskning kring hjärnan och dess belöningssystem och där tanken är att det i princip är samma avvikelse i belöningssystemet oavsett om det är frågan om missbruk av alkohol eller Internetanvändande.

Även om Petry (2006, p.142) möjligen har rätt när hon hävdar att "beteende addiktioner" delar många karakteristika med addiktioner relaterade till konsumtionen av heroin och kokain så finns det ändå en distinkt skillnad mellan en substansförankrad addiktion och en beteendemässig dito i den bemärkelsen att den förra kategorin har blivit identifierad som en addiktion med hänvisning till specifika egenskaper hos en begränsad uppsättning substanser I början av 1970-talet publicerade Smith \& Gay (1972) en bok med den tidstypiska titeln "It's so good do not even try it once - Heroin in perspective". Den påtagliga 
omsvängning från det tidiga 1970-talet har ett uppenbart pris, den underminerar möjligheten att hävda att vissa substanser i sig själva är kapabla till att förslava dem som använder desamma.

En betydande del av finansieringen av forskningen kring missbruk som en hjärnsjukdom tillfaller studier avsedda att identifiera och utveckla farmakologiska läkemedel för alkoholproblem (Room 2004). När det gäller läkemedelsbehandling för alkoholproblem har två preparat, naltrexon och akamprosat introducerats på markanaden under de senaste två decennierna. Trots att missbruksutredningen marknadsför dessa båda preparat med en uttalad entusiasm kan de knappast betraktas som några underkurer. I en aktuell systematisk översikt från Cochrane Collaboration (Rösner et al. 2010) konstateras att naltrexon i allmänhet har en liten effekt och att preparatet måste betraktas som ett supplement till, inte en ersättning för, psykosocial behandling. I konkreta tal måste nio individer behandlas med naltrexon för att en individ inte skall återfalla till tungt missbruk. Under de dagar individerna konsumerade alkohol reducerades naltrexongruppens drickande med 11 gram alkohol per dag (vilket motsvarar ett litet glas öl). En parallell översikt gällande akamprosat uppvisar i det närmaste identiska resultat (Rösner et al. 2011).

Det finns en påtaglig spänning mellan de framåtblickande kunskapspretentioner som artikuleras inom den neurobiologiska forskningen kring missbruk och de faktiska resultat som är för handen (Bergmark, 2008b). Ett av de tydligaste exemplen på detta utgörs av den mycket omfattande studien kring kombinatoriska effekter av bland annat naltrexon och akamprosat, den så kallade COMBINE studien (Anton et al. 2006). I ett supplement till prestigetidskriften Journal of Studies on Alcohol (från 2005, dvs. innan de viktigaste resultaten från COMBINE publicerades) ägnas nästan 200 sidor uteslutande åt den begreppsliga och metodologiska bakgrunden till varför en kombinerad medicinering med naltrexon och akamprosat bör leda till ett positivt utfall. Det grundläggande skälet till att kombinera dessa farmaka bygger på idén om additiva, eller till och med synergistiska verkningsmekanismer. Under det att naltrexon verkar på endogena opioider och därigenom förväntas minska de belönande effekterna av alkohol, är akamprosat tänkt att dämpa abstinenssymptom och därmed begränsa den negativa förstärkning som är associerad med upphörande av en mer omfattande alkoholkonsumtion. En postulering av sådana skillnader beträffande verkningsmekanismer öppnar givetvis upp för förväntningar om att en kombination av dessa två farmaka kan leda till en mer effektiv intervention. I en inledande artikel i det aktuella supplementet beskriver Mattson (2005) den nyare utvecklingen av behandling för alkoholproblem som ett "a giant step forward" och understryker att "our understanding of the neurochemical events underlying alcohol dependence has deepened" (s.7). Men när resultaten från COMBINE publiceras (Anton et al. 2006) och det står klart att inga som helst kombinatoriska effekter (inte det minsta spår) har identifierats och att vare sig naltrexon eller akamprosat har medfört några reella effekter utöver de som också har identifie- 
rats för placebointerventioner, lyser revideringarna av kunskapsläget med en total frånvaro.

\section{Ett utvidgat perspektiv på medikalisering}

I det föregående har vi gett exempel på hur såväl vetenskapliga som politiskt inriktade framställningar kring missbruk och behandling av missbruk som under flera decennier har varit inriktade på att medikalisera missbruksproblemen och att framställa missbruk som en sjukdom som skall behandlas med medicinska interventioner. Samtidigt står det också klart att det faktiska vetenskapliga underlaget för denna position måste betecknas som tämligen svag. Att denna avsaknad av samband mellan kunskapsläge och retorik har kunnat fortgå relativt ostört sammanhänger möjligen med en rad förändringar av centrala institutionella förhållanden inom det medicinska området i allmänhet, förändringar som ger för handen att de begreppsliga ramarna för medikaliseringsprocesser bör vidgas.

Vi har tidigare pekat på det faktum att medikaliseringsprocessen över tid har ändrat karaktär från att för 30 år sedan ha varit en transformering "from badness to sickness" (Conrad \& Sneider 1980) till att idag huvudsakligen vara en process inriktad på att transformera ovetenskap till vetenskap. Denna tendens till medikalisering som en följd av ett krav på en radikaliserad rationalitet, innefattar ett flertal besläktade företeelser som standardisering, kommodifiering, transparanta proce- durer, elektroniska nätverk, databaser, och evidensbaserad medicin (EBM).

En av de viktigaste utgångspunkterna för utvecklingen av ett mer expansivt medikaliseringsbegrepp har varit försöken att komma tillrätta med en betydande variation i medicinsk praktik. En sammanfattande term för dessa ansträngningar inom det medicinska området är EBM, som i en förenklad form skulle kunna beskrivas som en uppsättning metodologiska procedurer avsedda att extrahera slutsatser kring olika medicinska interventioner på basis av befintliga vetenskapliga effektstudier. Utvecklingen av EBM har över tid också medfört en påtaglig tendens till att försöka standardisera den medicinska praktiken, framförallt via produktion av kliniska riktlinjer. Särskilt i de fall då riktlinjer knyts till kvalitetsindikatorer och finansiering får byråkratiska instanser möjligheter att hålla producenterna ansvariga för kvalitén på de interventioner som kommer till användning.

Standardiseringen av interventioner har också medfört en kommodifiering av de tjänster som erbjuds. I de fall det finns nationella kvalitetsregister att tillgå kan dessa numera inte bara användas av producenter och finansiärer, det finns nu också en offentlig transperens som gör att presumtiva patienter kan granska den aktuella informationen för att göra informerade konsumentval (Bohlin 2011).

Övergången från ett traditionellt medikaliseringsbegrepp till ett mer sammansatt och expanderande som antyds ovan har av vissa forskare betecknats som biomedikalisering. Clarke et al. (2003) använder denna term för att beskriva vad de kallar en andra 
transformering av amerikansk medicin. Denna transformering innefattar bland annat komponenter som den biomedicinska forskningens omfattning och villkor, en ny fokusering på hälsa och riskhantering, ökande teknologisk/vetenskaplig utveckling av det biomedicinska området, och en transformering av hur kunskap produceras, distribueras och konsumeras. Också nestorn inom medikaliseringsforskningen, Peter Conrad (2007), pekar på nödvändigheten att identifiera de förändringar som har skett under de två sista decennierna.

Kraften hos den nutida medikaliseringsprocessen och den samhälleliga betydelsen av densamma kan knappast överskattas. Socialtjänsten och det sociala arbetet har träffats av en flodvåg av påverkan som innefattar krav på såväl kundorientering och evidensbaserad praktik. Dessa krav framstår som icke förhandlingsbara utifrån ett medi- cinskt perspektiv samtidigt som kraven knappast kan sägas vara tillräckligt anpassade till det sociala arbetets kontext; missbruksbehandling är inte jämförbar med en höftledsoperation (i det första fallet finns ofta ett mer eller mindre direkt tvång närvarande, i det andra fallet står individer i månadslånga köer för att få del av interventionen). Experimentella studier av psykosociala interventioner kan inte studeras med samma typ av experimentella design som olika farmaka. De skillnader som finns mellan det medicinska området och det sociala måste ges en reell plats i de analyser som genomförs, i annat fall kommer de centrala doktrinerna från det medicinska området att legitimera en fortsatt medikalisering av socialt baserad missbrukarvård utan att ta någon hänsyn till att det vetenskapliga stödet för en sådan förändring $\mathrm{i}$ allt väsentligt är frånvarande. 


\section{Referenser}

Anton, R., O'Malley, S., Ciraulo, D., Cisler, R., Couper, D., Donnovan, D., Gastfriend, D., Hosking, J., Johnson, B., LoCastro, J., Longbaugh, R., Mason, B., Mattson, M., Miller, W., Pettinati, H., Randall, C., Swift, R., Weiss, R., Williams, L. \& Zweben, A. (2006) Combined Pharmacotherapies and Behavioral Interventions for Alcohol Dependence. The COMBINE Study: A Randomized Controlled Trial. JAMA, 295:17: 2003-2017.

Berglund, M., Thelander, S. \&Jonsson E. (2003) Treating Alcohol and Drug Abuse: An Evidence Based Review. Viernheim: Wiley-VCH.

Bergmark A. (2001) Om den evidensbaserade missbrukarvårdens retorik och praktik. Nordisk Alkohol- och Narkotikatidskrift, 18:2, 133138.

Bergmark, A (2008a) Om evidensbasering, kunskapsöversikter och psykosociala mekanismer. I Meuwisse, A., Swärd, H. Eliassons-Lappalainen, R. \& Jacobsson, K. (red.) Forskningsmetodik för socialvetare, Stockholm: Natur \& Kultur.

Bergmark, A. (2008b) On treatment mechanisms - what can we learn from the COMBINE study. Addiction, 103:703-705.

Bergmark, A. (2008c) Specific and contextual treatment mechanisms. Nordic Studies on Alcohol and Drugs, 25:277-285.

Bergmark, A. (2010) Den vetenskapliga grunden för psykosocial missbruksbehandling; Socionomens forskningssupplement, 28:20-27.

Bohlin, I. (2011) Evidensbaserat beslutsfattande i ett vetenskapsbaserat samhälle. Om evidensrörelsens ursprung, utbredning och gränser. I Bohlin, I \& Sager, M (red) Evidensens många ansikten. Lund: Arkiv förlag.

Clarke, A., Shim, J., Mamo, L., Fosket, J.. \& Fishman, J. (2003) Biomedicalization: Technoscientific Transformations of Health, Illness and the U.s. American Sociological Review, 68: 161194.

Conrad, P. (2007) The Medicalization of Society.
Baltimore: The John Hopkins University Press. Conrad, P. \& Schneider, J. (1980) Deviance and Medicalization. From Badness to Sickness. St. Louis: Mosby.

Mattson, M. (2005) Conceptual and Methodological Foundations of COMBINE. Journal of Studies on Alcohol, supplement 15:6-7.

Missbruksutredningen (2009) Beroendevårdens organisation och resurser i fem län - en kart läggning. Socialdepartementet, Stockholm. Petry, N. (2006) Should the scope of addictive behaviours be broadened to include pathological gambling. Addiction, 101:152-160.

Room, R. (2004) What if we found the magic bullet? Ideological and ethical constraints on biological alcohol research and its application. In Müller, R. \& Klingemann, H. (ed.). From Science to Action? 100 Years Later - Alcohol Policies Revisited. Dordrecht: Kluwer,

Rösner, S., Hackl-Herrwerth, A., Leucht, S., Vecchi, S., Srisurapanont, M. \& Soyka M. (2010) Opioid antagonists for alcohol dependence. The Cochrane Library, Issue 12.

Rösner, S., Hackl-Herrwerth, A., Leucht, S., Lehert, P., Vecchi, S. \& Soyka, M. (2011) Acamprosate for alcohol dependence. The Cochrane Library, Issue 2.

SBU (2001) Behandling av alkohol- och narkotikaproblem. En evidensbaserad kunskapssammanställning (volym I och II). SBU- Statens beredning för medicinsk utvärdering, Stockholm.

SOU 2011:6 Missbruket, kunskapen och vården, Stockholm, Socialdepartementet.

SOU 2011:35 Bättre insatser vid missbruk och beroende - Individen, kunskapen och ansvaret, Stockholm: Socialdepartementet.

Takala, J-P. \& Lehto, J. (1992) Finland: The NonMedical Model Reconcidered. In Klingeman, H., Takala, J-P. \& Hunt, G. (eds.) Cure, Care or Control. New York State: University of New York Press. 


\section{Summary}

\section{The medicalization of Swedish treatment of substance abuse}

It is a well-known fact that the care of addicts in Sweden and in the Nordic countries (Finland, Norway, but not Denmark), unlike the majority of other Western countries, over a relatively long period has been characterized by a social perspective on the fundamental nature of different types of substance abuse problems. This has meant that the actual handling of the substance abuse problem by and large has also been a concern for social rather than medical personnel. Meanwhile, it is also very clear that this regime has been exposed to relatively high pressure for a relatively long time. Ten years ago the Swedish Council on Technology Assessment in Health Care (SBU) published their extensive knowledge review regarding the treatment of alcohol and drug problems: "The treatment of alcohol and drug problems: An evidence-based knowledge review". This publication, together with a more recent report from a Government commission concerning the knowledgebase and future organization of substance abuse treatment (SOU 2011:6), forms the core material for the analysis presented in this article.

In the analysis several examples of how both scientific and policy-oriented representations concerning addiction and addiction treatment of several decades have been aimed at medicalizing addiction problems and producing an image of a disease that needs to be treated with medical interventions. At the same time it is also clear that the actual scientific evidence for this position must be considered rather weak. The fact that this lack of correlation between the level of knowledge and rhetoric has been able to continue relatively undisturbed is possibly associated with a number of changes to key institutional relationships in the medical field in general, changes which indicate that the conceptual framework of the medicalization process should be broadened. 